\title{
A Future Vision for the College Instructors' Use of Achievement (Paper-Electronic) Files as Modern Methods to Evaluate Their Students at Ajloun University College
}

\author{
Aiman M. Freihat \\ Department of Evaluation and Measurement at Educational Sciences, Ajloun University College, Al- Balqa Applied University, Jordan
}

Received June 22, 2020; Revised September 11, 2020; Accepted September 29, 2020

\begin{abstract}
Cite This Paper in the following Citation Styles
(a): [1] Aiman M. Freihat, "A Future Vision for the College Instructors' Use of Achievement (Paper-Electronic) Files as Modern Methods to Evaluate Their Students at Ajloun University College," Universal Journal of Educational Research, Vol. 8, No. 11B, pp. 5735 - 5748, 2020. DOI: 10.13189/ujer.2020.082208.
\end{abstract}

(b): Aiman M. Freihat (2020). A Future Vision for the College Instructors' Use of Achievement (Paper-Electronic) Files as Modern Methods to Evaluate Their Students at Ajloun University College. Universal Journal of Educational Research, 8(11B), 5735 - 5748. DOI: 10.13189/ujer.2020.082208.

Copyright $\bigcirc 2020$ by authors, all rights reserved. Authors agree that this article remains permanently open access under the terms of the Creative Commons Attribution License 4.0 International License

\begin{abstract}
This study investigated the importance of using the achievement file, in both electronic and paper forms, as an evaluation instrument to document the performance of both teachers and students. The researcher planned the question in the following question: What is the future vision of the college members' use of achievement (paper-electronically) files, at the Ajloun University College, as modern methods for evaluating their students? The researcher used the descriptive-differential analytical approach. The researcher noticed, through observation and interview, that many previous relevant studies were reviewed to clarify the mechanism of using the (paper-electronic) achievement files. The study presented some results related to the quality of students' learning, the quality of the educational process, and others related to the quality of the used evaluation method. This study provided a future vision of the college members' use of the achievement files to evaluate the expected learning in several disciplines: knowledge (cognitive skills), dealing with others, taking responsibility, communication skills, information technology (IT), numerical skills, and psychomotor skills. The researcher recommended educating the university community about the culture of developing students' evaluation systems and exams to improve the educational system and ensure its quality. This could be done by spreading the culture of evaluation and
\end{abstract}

exam development. Besides, students should be taught from the beginning about their roles and what was required from them with every step of the process of using the achievement file in their evaluation. Students should be provided with instruments, guiding them to the resources that would help them accomplish the work included in the file.

Keywords Achievement (Electronic-Paper) File, Ajloun College Members, Evaluation

\section{Introduction}

The evaluation has an important place in our lives by which we define our achievements and what we have fulfilled because of these actions. Evaluation is an essential component of the educational structure and system as conducting one of these didactic processes cannot be completed without evaluation procedures and practices. Therefore, evaluation is one of the most important links of the educational system comprising the teacher, student, and curriculum. Without evaluation and the accredited standards, the application of the principle of justice and equal opportunities will be absent among graduates of the 
same department, college, and university. Thus, work was still in planning the evaluation criteria for all parties regarding the educational process, updating, developing, and keeping pace with all current technological developments.

The teaching and learning system cannot develop by using traditional evaluation systems that focus on measuring the minimum levels of the cognitive sides of students. Neglecting the other aspects of learning, there will be graduates who do not fulfil the local and global labour market that rely on higher learning skills (Odeh, 2014).

The development of student- evaluation systems gets the priority in all countries because it is impossible to make tangible progress at the level of university -education institutions without improving the quality of university performance and keeping pace with global developments in this field. The transition towards applying modern methods to student evaluation avoids the use of traditional, outdated methods.

Among the most critical challenges facing universities in this era, are the various developments in all fields. The more successful university achieved in its outputs, the newer aspirations, imposed by a rapid life, were. Hence, the importance of the student- evaluation system lies in its impact on raising the quality of university performance.

Considering the distinguished position that a college member occupies in university education and the role he or she plays in the fields of scientific research, education, community service, development, and the efforts made by those who are in charge of them to achieve its goals and continuously improve their level of performance, however, universities' exertion can only be done via the authentic (real) evaluation. The provision of clear and specific criteria emanating from the college member can only achieve the authentic evaluation. The achievement file, in both electronic and paper forms, is considered one of the evaluation methods that contribute to developing the work of the college member at the university.

The electronic achievement file is considered being a modern technological innovator that is used in the evaluation. It is regarded as a scientific evaluation instrument based on specific criteria. Its importance has increased in education as it documented the performance of both the teacher and the student. Therefore, this study came to discuss these methods.

\section{The Study Questions}

The educational systems, globally and locally, are witnessing a comprehensive development in the field of evaluating student learning. This requires those in charge of the education process, including college instructors, decision-makers and educators, to be updated on the latest developments in this field. Recent trends in the evaluation have indicated that tests are a form of evaluation. This calls for achieving a comprehensive evaluation characterized by success, dealing with other forms of evaluation that reflect the reality of the learner in a certain ability and showing the positions of strength and weakness in him, to develop that ability accordingly. Thus, they raise the level of education, and until this is achieved, the student must be evaluated more from one way, and in more than one situation. The strategies of realistic evaluation, specifically the portfolio of achievement (Portfolio), provide the teacher with other methods of evaluation that integrate with the method of exams (paper and pen) and thus improve the educational learning process.

The researcher, through his observation during work as a college member at Al Balqa Applied University, Ajloun University College, noticed difficulties in evaluating students' educational outcomes. He relied only on tests that were sometimes mixed with personal feelings and relationships with the students. He also noticed a great deficiency among students in documenting their work, activities, and learning outcomes throughout the study period. Besides, the researcher observed the weak formation of accumulated experiences among students because of assignments, activities, and various duties they perform during the study.

Besides, the researcher noted the students' attachment to technology and their possession of many smart devices. They used these devices to record their daily lives, whether they are pictures, video clips or quick words, or record audio clips. They exchange or store these electronic recordings or make adjustments to them through ready programs loaded on these devices.

Based on the observations and interviews, the researcher reviewed previous related studies, in the domain, of electronic achievement files. The study of Illera, Rodriguez, Lopez-Fernandez (2009), for example, confirmed that the electronic achievement file has a growing importance in higher education. It was an educational and evaluation instrument built on the student's control of his or her virtual learning environment. The study aimed to analyse the perceptions, attitudes, and behaviours of students at the university level. The study used the electronic achievement file to support learning and evaluation. The results showed that the positive views of students, about their self-efficacy of using the file, emphasized the importance of the achievement file as a growing self-learning instrument.

\subsection{Previous Literature}

There were a lot of studies that dealt with realistic evaluation and a variety of methodologies adopted in its study, which gave greater confidence in the findings of those researches. Some researchers took the qualitative approach as a way and collected their data based on interviews and observations in addition to studying and 
analysing evaluation instruments. By referring to the literature of measurement and evaluation, we find that the names that guide this term are numerous, and the most prominent of them are: Performance-based calendar, natural calendar, authentic calendar, constructive calendar (Keyser, \& Howell, 2008), alternative calendar, and direct calendar (Mueller, 2012). Despite the difference in these nomenclatures, they all emphasize a performance-based change in evaluating learning outcomes.

MacMillan (2001) defined six types of alternative evaluation:

Authentic Assessment.

Performance Assessment.

Portfolio Assessment.

Exhibition (Exhibition Assessment).

Demonstration assessment.

Student's Self Assessment.

Suurtamm (2012) conducted a study that examined the beliefs and concerns of five college instructors distributed over four different schools over the course of a whole year (a case study). She used several methods to collect the study data. She conducted several interviews with each participant separately, asking to what extent the teacher used the realistic evaluation. Besides, she asked the college instructors about their views of learning mathematics and the relevant resources in the realistic evaluation. Suurtamm followed the method of direct observation while using the methods of realistic evaluation. Suurtamm followed every process of interviewing and observation, studying the realistic evaluation instruments used by college instructors and some of the students' answers to these instruments. The results of the study indicated that the participating college instructors believe in using realistic evaluation methods. They believe that it develops thinking and questioning -solving skills among their students. It also increases the understanding of mathematical concepts more than focusing on the method and procedures, developing the skill of thinking in metacognition.

Suskie (2004) conducted a study that aimed at studying the Rubrics scale. The study showed that this instrument helps the teacher and the student to study the partial details of the mark and the student's points of strengths and weaknesses. This instrument also helps students understand the teacher's expectations about them, improving their performance, and increasing communication between teacher and student.

Al-Rifai, Twalbeh, and Al-Qaoud (2012) conducted a study that aimed at knowing the degree of the practice of social studies college instructors in the intermediate basic stage of realistic evaluation strategies. Besides, it identified the effect of gender, experience, and academic qualification variables on the degree of practicing these strategies. The results showed that the degree of college instructors' practice of realistic evaluation strategies is average. There were significant differences attributed to gender in favour of males. There were academic qualification differences that went for the bachelor's degree. Also, there were no differences attributed to the experience variable.

Afaneh (2011) conducted a study aimed at identifying recent trends in evaluation. It also highlighted the reality of the Arabic language college instructors' use of the alternative evaluation methods in the preparatory stage in UNRWA schools in the Gaza Strip. His study aimed to determine whether there is a difference in the use of evaluation methods due to the gender variable. The results showed that the total degree of male college instructors' use of modern evaluation methods reached (45.1\%). The written- test evaluation method ranked first. The observation-based evaluation method came second. As for the female college instructors only, the percentage of using the modern evaluation methods was $(58.3 \%)$. The written test- performance evaluation ranked first, followed by the oral performance-based evaluation.

\subsection{Commenting on Previous Studies}

From previous studies, it is evident from the diversity of methods and fields of dealing with the subject of realistic evaluation by researchers. This may be due to the desire to improve the level of the educational process and its outcomes with all its variables. The increasing interest in comparing the characteristics of individuals across different groups, regarding the language and cultures of the necessary educational practices, is characterized by rapid development towards globalization. The accuracy of the decision in any humanitarian field depends on the quality and accuracy of the data, and the extent of its coverage of the variables in the field of research, which makes the topic of research in this area fertile and useful locally and globally, but there was a lack of study of the degree of knowledge and the use together of realistic evaluation strategies. There were studies measuring use, but those studies did not study at the local or regional level (according to the researcher's knowledge) the degree of knowledge, for the use of paper and electronic license files as modern methods for evaluating university students, but most of them were limited to the students of the teacher because through the meetings that the researcher conducted during Study application with the college instructors of Ajloun University College. Many college instructors reported that their lack of knowledge of instruments and strategies prevents the use of this strategy, which may prompt officials and decision-makers to focus on conducting a survey study aimed at identifying the needs of college instructors in the college in terms of methods and means to help them apply realistic evaluation strategies (Portfolio).

The study of (Beresford \& Cobham, 2010) looked at web instruments 2 as the extent of students maintaining electronic records of their learning, electronic achievement 
file as a learning instrument. The results of the study showed the benefit achieved from the electronic achievement file for its contribution to their development.

The study of (Ozgur, 2011) adopted the introduction of the electronic achievement file in the training program for teachers. The study intended to assist supervisors in evaluating teachers' performance and their outputs before getting into service. It focused on designing, implementing, and evaluating the electronic achievement file in the program to improve the electronic counselling system that is a cornerstone of implementing the achievement file.

Arter and Spandel (1992) defined a portfolio as a meaningful gathering of student work that showed his or her efforts, progress, or achievement in a particular field of study. This gathering should include the participation of students in choosing the content of the portfolio and the criteria for judging its quality and evidence of the student's implications for it.

Leavell (1996) saw that the portfolio had many educational advantages since its use in the classroom made integration between the evaluation and education processes. Besides, it made the teacher and students more interested in a wide range of important tasks and activities. It allows students to take part in the evaluation process by providing them with the opportunity to select some assignments, self-assessing them, and thinking about their accomplishments. It also helps teachers examine their students' learning processes and outputs, revealing their growth and affecting all aspects of the teaching and learning process through time.

It is essential to have a university- development project preceding academic studies that defined and highlighted the need to diversify evaluation methods. Also, they used modern technologies to ensure the quality of the outputs. Hence, this study came to develop a future vision for the use of college members of electronic and paper achievement files as modern instruments while evaluating their students.

The researcher identified the question of the deficiencies in evaluating various university courses. The researcher planned the study question: "What is the future vision of the college members' use of the achievement (paper electronic) files as modern methods to evaluate their students at the Ajloun University College?"

\section{Significance of the Study}

The importance of the current study stems from the importance of the topic itself, as the evaluation is one of the most important educational programs that affect the formation of the educational model. It also raises its efficiency and effectiveness. Evaluation, based on correct vision, leads to building reliable scientific evaluation instruments through which evidence can be collected. This evidence leads to correct judgments about students' achievements and thus improving teaching and learning processes.

The importance of this research also stems from increasing the awareness of college instructors and students of the importance of this type of evaluation, and its impact on students' learning and information retention. This prompts university administrations and those in charge of education to follow up and overcome the difficulties that university college instructors face during its implementation. This study also contributes to identifying the current reality of the evaluation practices and instruments used by university college instructors. Besides, this study aims to direct the officials' attention to the reality of using evaluation strategies and the obstacles it encounters. Also, it attempts to raise the performance levels that are still below the required ones like the International Tests (PISA and TIMSS) held in Jordan.

The current research may avail those who are in charge of the educational process in higher education. It may help them adopt the use of the (paper- electronic) achievement file in the learning process and in evaluating students.

Arab environmental studies and researches lack studies that address the effect of electronic achievement files in assessing the integrated growth of students' mental skills during their studies. Thus, this study may pave the way for other related studies to use electronic achievement files, using them as a standard for evaluating students in different colleges.

It may contribute to providing students with the benefits of having the uniqueness of education and unique skills. It depends on the subject and the interests of the student to promote self-assessment by knowing their strengths and weaknesses.

\section{Study Objectives}

- To know the future vision of the college members' use of (paper-electronic) achievement files in evaluating their students.

- To identify the expected results from the college members' use of electronic achievement files in assessing student learning.

- To promote self-assessment among students at the university.

\section{Study Terms}

\subsection{Evaluation}

It is a systematic process that requires the collection of objective data and valid information using various measurement instruments scientifically to make judgments to students and the educational process. It is to improve the quality of performance, raising the efficiency of the 
students' improvement and development. Thus, it is a diagnostic and therapeutic process at the same time. The Evaluation identifies the strengths and weaknesses and treats deficiencies by all possible means (Odeh, 2014).

Therefore, we can deduce the comprehensive formula that is called the procedures for evaluating students compared to their assessment. The evaluation of students is broader in its procedures than their assessment. Evaluation surpassed assessment in making judgments of value or making educational decisions built on the data given by the evaluation.

\subsection{Achievement File or Portfolio}

It is a guided gathering of the student's work that explains his or her efforts, progress, or achievement in a specific field of study. This collection should include the participation of students in choosing the content of the portfolio, how it is chosen, the criteria for judging its quality, and evidence of the student's impressions of it. This file is a reference for following-up on students' levels and progress (A'llam, 2015).

\subsection{Electronic Achievement File (Electronic Portfolio)}

It is an electronic file in which students electronically collect all their duties to select the best distinctive assignments, of lessons, lectures, projects, and exercises in a course or group of courses, to handle by the teacher (A'llam, 2015).

\section{Study Methodology and Procedures}

\subsection{Study Methodology}

In this study, the descriptive and analytical method was used, which is concerned with describing the degree of knowledge of college instructors in Ajloun College and their practice of realistic evaluation strategies and instruments achievement files.

\subsection{Study Limitations}

This study was limited to Ajloun University College students for the academic year 2019-2020

\subsection{Study Community}

The study population comprised all the (139) students of Ajloun University College / fourth year in the Specialty of psychological counselling.

\subsection{The Study Sample}

The questionnaire was distributed to all instructors of the study community, whose number is (139) male and female students, and after close follow-up by the researcher, (115) questionnaires were retrieved, i.e. approximately (83\%), which is a very acceptable percentage for the study according to the educational literature (Gay \& Airasan, 2003). The researcher excluded (24) questionnaire- responses either due to the lack of seriousness or the lack of completion of some of them. And thus, the study sample comprised (91) male and female students.

\subsection{The Questionnaire as the Instrument}

The researcher developed a questionnaire comprising three parts: The first part related to special data about the teacher in the college, and the second part related to the college instructors 'knowledge of realistic assessment strategies and instruments (portfolio). The third part discussed the reasons for college instructors' use of realistic evaluation strategies and instruments, the instrument was built through the researcher's acquaintance with previous studies and what was mentioned in educational literature, and through the focus groups that the researcher intended from the college's college instructors and students. The researcher asked questions to these different groups regarding the evaluation of the paper and electronic achievement files. The researcher recorded their observations for drafting the items of the questionnaire.

\subsection{Validity and Reliability of the Questionnaire}

To verify the indications of the validity of the instrument, the instrument was presented in its initial form to referees comprising (12) university professors with a doctorate in measurement and evaluation. The reliability of the instrument was verified using the method of application and re-application at a rate of two weeks between the first and second application, according to the reliability coefficient, which was (0.879).

\subsection{The Application}

The researcher applied the study instrument to the respondents in the second semester of the 2019/2020 academic year. The researcher also applied the observation card to (27) male and female college instructors who had a reasonable approach towards using the realistic evaluation. The researcher paid one visit per college member. The researcher applied the last part of the questionnaire to them to investigate the degree of accuracy in practice.

\subsection{Study Design}

The researcher used the descriptive- analytical method. This method is concerned with describing the degree of college instructors' knowledge and practice of paper and electronic evaluation strategies at the university. 


\section{Theoretical Framework}

\subsection{Student's Portfolio}

It is one instrument that has an important position among the instruments of the original evaluation. And this file expresses our need to provide an instrument that helps us continuously and electronically evaluate the student's performance. It is to provide clues or documented evidence of the progress of his or her learning.

The student's achievement file is used to display a sample of his or her work and performance rate. He or she is, thus, a witness to his or her skill, ideas, inclination, and accomplishments. This file may include selected reports, notes for revised writings, a laser disk, on which a student's achievement is stored, or audiovisual tapes, or pictures.

The word "Portfolio" comprises two syllables, which is "Port", meaning carrying, and "Folio" to mean paper. This term applies to many definitions that try or explain it. A self-reflection of the student in those assignments is more than just a random compilation of the student's work. It is an organized and guided combination of these assignments that the student takes part in choosing and organizing them.

The student's achievement file involved an evaluation of the recognition that teaching and evaluation were two parallel processes. Spending time and effort in directing the student to create and evaluate this ultimately increases the student's education and the progress of his or her performance. The student's achievement file is an assessment and educational instrument at the same time.

The student's achievement file is also a mirror that reflects his or her academic life in a cognitive field. It is a record of the story of his or her efforts and performance in this field. Its popularity has increased among educators who started using it because it achieves many advantages, besides being an effective evaluation instrument; it is interested in evaluating the student's performance by learning, not by the result. This file as a distinctive instrument is used to:

1. Organize and express the students' ideas.

2. Learn, discover, review, and develop the self.

3. Communicate and cooperate between the student and the teacher, and between the student and his or her colleagues.

4. Develop the student's capabilities, ideas, information, and experience.

5. Develop creativity, taking responsibility to build self-confidence.

Among the many advantages of the students' achievement files, we can easily conclude that it is an indispensable instrument for us while developing our student's evaluation. Besides, it goes for the benefit of students, teachers, the learning process, and the learning environment.

The various advantages of the students' achievement files reflect multiple uses for them. They are not limited to the evaluation only, but also extend to other usages that we refer here to three of them:

\subsection{Student's Achievement File as a Portfolio Presentation}

It aims to show the higher level the student has achieved in education as if he or she is telling us this is the level that I have reached, and this file includes the distinguished assignments and achievements that the student wants to display.

\subsection{Student's Achievement File as a Learning Portfolio File}

It aims to provide testimony to the quality of education as it includes the student's work that he or she carried out in stages to achieve the specified educational goals and thus showing the student's graduation in the education process. And therefore, it is sometimes called the graded file, and it includes all the completed and unfinished assignments along with the student's vision and comments thereon.

\subsection{Student's Achievement File as an Evaluation Portfolio}

It aims to evaluate the student's progress toward educational goals during a period of study and also at its end. The evaluation file provides opportunities for college members to practice both structural and final evaluations. The self-assessment by the student of his or her assignments in this file is the first step towards structural evaluation.

The organization of the student's achievements file is subject to a specific structure governed by the crucial dimensions of the teaching process, namely the method of teaching. It makes the student more responsible for his or her learning, self-assessment, and evaluation, and then it must be well- organized so it includes:

- An innovative title page that reflects the student's personality.

- A content index that provides the reader with an overview of the work included in the file.

- Written student's justifications explaining the reason for choosing each work.

- The history of each assignment to be linked to the stages of learning.

- Teachers' and others' comments on work, feedback, response, and encouragement.

\section{Electronic Achievement File}

The trend towards moving from using the (traditional) paper achievement file to the electronic achievement file has received an impressive deal of support over the past 
few years from the perspective of teacher preparation programs. It is because the electronic achievement file contains the same information that the traditional paper files contain. Still, the critical difference between them lies in electronically collecting, storing, and managing information (Lambert, 2007).

The electronic achievement file is one of the modern methods used in education as it is an effective objective evaluation instrument based on specific criteria. It also enhances the student's performance and develops several skills, including organization, presentation, and thinking skills. It also documents the student's performance. It provides him or her with the opportunity to refer to previous experiences that make him or her improve his or her performance.

Besides, the evaluation of the electronic achievement file is not an alternative to the traditional study tests used in the evaluation process. It is also an effective instrument to provide teachers with the opportunities to link between their professional training experiences and their practical experiences in teaching in the classroom. Also, it contemplates the various interpretations and provisions issued to students (Wang, 2004). The electronic achievement file is used as an effective instrument to truly evaluate students on a large and increasing scale in the college instructors' preparation programs. It is used to document their levels of professional advancement and their different skill levels.

This is because it provides teachers, in the pre-service stage, with many benefits, such as:

1. Increasing the refinement of scientific skills to deal with advanced technology.

2. Enabling practical education teachers to show their ability to use this advanced technology effectively.

3. Documenting students' academic progress levels and encouraging them to develop besides motivating them to take part in learning, self-evaluation, and contemplative learning.

4. Making significant changes in the roles of students, so they shifted from playing the roles of passive students to the roles of positive ones. Positive students are the ones who could enjoy the activity, planning for the future, critical thinking, and learning design (Wang 2007).

Barrett (2007) also pointed out the most prominent advantage of the electronic- achievement file, which is the use of advanced technical methods as a didactic instrument for teachers or students. It can be used to collect and organize the students' learning outcomes by using various forms and templates as sound, graphics, video, and written texts. Besides, it can use hyperlinks to high-level texts in organizing the subject of electronic achievement. It is used to link the clues about students' academic progress with their achievement of the outcomes and goals that are previously set for them.

\subsection{General Principles for Designing the Electronic Achievement File}

Effective design of the achievement file requires adopting a common set of theoretical principles and effective teachers', educational designer's, educational program managers', administrators, and technical specialists' practices which are:

1. Learning Outcomes: To guide students during learning by providing them with precise criteria that define their learning and methodological outcomes. This could be done when collecting, selecting, and presenting their learning outcomes in the form of electronic documents and files within the framework of electronic documentary bags. By organizing the contents of their electronic educational bags, students would be related to their own learning goals.

2. Digital environments: Taking advantage of the various applications of the electronic bag to be easily accessed via the Internet.

3. Responsibilities Assigned to all Members of the educational system: Students receive support from teachers, educational program managers, technical specialists, and educational designers. They work to use the electronic achievement file to measure the extent to which they achieved the goals and the development of applied educational programs. They also work continuously on getting authentic information about what resources they need to implement, develop, and achieve quick and easy access to the student's online achievement file.

4. Meditating and Teaching How to Cooperate with Electronic Achievement Files: Students work to design and present contemplative learning outcomes that enable them to identify and evaluate learning that their electronic facts represent. Particularly, students can explain how their reception affected several teaching feedbacks from teachers, educational supervisors, and others about their abilities to review the learning outcomes of their various e-bags.

5. Integration and Correlation with the Established Curricula: Students work to link their learning outcomes flexibly that contribute to mix and compose some original ideas about learning. This encourages students to use various written or oral (interactive) methods in reading and evaluating their electronic bags. Besides, the electronic achievement file establishes close links with the clues about student's learning through the provided electronic achievement file and various learning sources. Hence, students can benefit from these close links in representing the electronic learning achievement files presented with the contents of the curricula.

6. Virtual Identities: Students represent themselves when presenting their personal information. Electronic achievement files, as a web-based 
instrument, are intended to intentionally identify their personality and learning outcomes.

7. Lifelong Learning: Students, who use the electronic achievement file, can adjust and adapt learning to suit their use in achieving various goals and practical applications. By doing so, the learners will be immersed in the non -scheduled academic contents. Thus, diverse readers can continuously monitor their levels of lifelong learning via

\subsection{Characteristics of Electronic Achievement Files}

The characteristics of electronic achievement files are determined according to (Zellers\& Mudrey, 2007):

1. Focus on the student's performance: it allows the student to choose what to include in the achievement file, of objectives, content, and self-understanding expression, he or she will present to the teacher.

2. Continuous development of learning outcomes: The files invest the students' tendencies to save their work, allowing them to have a second look at their work and think about how to improve and change it. This may contribute to developing critical and creative thinking, question -solving skills, and self-organizing skills.

3. The orientation of gaining efficiencies: Competencies that are gained or fully proficient at the starting point for preparing the achievement file. The achievement file can be a representation of the competencies that the academic course hopes to provide the student with. The student must know that the required competencies needed more practice, so electronic achievement files were reliable because they were accurate representations of the students' achievements.

4. Multimedia Orientation: The student chooses the media that he or she used to display his or her work in the file, requiring skills to deal with multimedia. This provides the student with the opportunity to promote his or her in using multimedia. Also, it allows the student to represent information in distinct ways more than obligating him or her with one response, leading to improve knowledge via using technology.

5. Depending on Action and Reaction: The student will develop a personal plan to build his or her electronic file which may contain a series of activities following the self-feedback of the teacher and colleagues. The student adjusts the file and its contents to reach the required level, which leads to developing his or her achievement file.

\section{Results Display and Discussion}

\section{Results related to the first question: What is the degree of knowledge and practice of Ajloun University College instructors of realistic evaluation strategies (achievement files)?}

This question was answered by responding to the second part of the questionnaire presenting the college instructors' responses (male and female separately). Their responses were in the form of frequencies and percentages to answer (yes) to the item "Yes I know", or (yes) for " I use". See table (1).

Table 1. Frequencies and percentages of college instructors who answered (yes) for " I know the strategy", and (yes) " I use the strategy."

\begin{tabular}{|c|c|c|c|c|c|c|c|c|c|}
\hline \multirow{2}{*}{ Number } & \multirow{2}{*}{ The Strategy } & \multicolumn{2}{|c|}{$\begin{array}{c}\text { Frequencies and Percentages of College Instructors } \\
\text { who answered (yes) to "I know the strategy" }\end{array}$} & \multicolumn{3}{|c|}{$\begin{array}{c}\text { Frequencies and Percentages of College } \\
\text { Instructors who answered (yes) to " I use the } \\
\text { strategy" }\end{array}$} \\
\cline { 3 - 10 } & $\begin{array}{c}\text { Males' } \\
\text { Number }\end{array}$ & $\begin{array}{c}\text { Males' } \\
\text { Percentage }\end{array}$ & $\begin{array}{c}\text { Females' } \\
\text { Number }\end{array}$ & $\begin{array}{c}\text { Females' } \\
\text { Percentage }\end{array}$ & $\begin{array}{c}\text { Males' } \\
\text { Number }\end{array}$ & $\begin{array}{c}\text { Males' } \\
\text { Percentage }\end{array}$ & $\begin{array}{c}\text { Females' } \\
\text { Number }\end{array}$ & $\begin{array}{c}\text { Females' } \\
\text { Percentage }\end{array}$ \\
\hline 1 & $\begin{array}{c}\text { Performance-ba } \\
\text { sed evaluation }\end{array}$ & 28 & $65.1 \%$ & 34 & $70.8 \%$ & 5 & $11.6 \%$ & 13 & $27.1 \%$ \\
\hline 2 & $\begin{array}{c}\text { Presentation- } \\
\text { based } \\
\text { evaluation }\end{array}$ & 26 & $60.5 \%$ & 38 & $79.2 \%$ & 12 & $27.9 \%$ & 17 & $35.4 \%$ \\
\hline 3 & $\begin{array}{c}\text { Demonstration- } \\
\text { based } \\
\text { evaluation }\end{array}$ & 33 & $76.7 \%$ & 40 & $83.3 \%$ & 20 & $46.5 \%$ & 25 & $52.1 \%$ \\
\hline 5 & $\begin{array}{c}\text { Paper-and-penci } \\
\text { levaluation }\end{array}$ & 43 & $100 \%$ & 48 & $100 \%$ & 43 & $100 \%$ & 48 & $100 \%$ \\
\hline 6 & Work Sheets & 43 & $100 \%$ & 48 & $100 \%$ & 33 & $76.7 \%$ & 43 & $89.6 \%$ \\
\hline
\end{tabular}


Table (1) shows that the college instructors' responses to items (4) and (5) regarding the use of the two strategies of paper-and-pencil and worksheets, respectively, got $(100 \%)$. It is because of their convictions that they are the most appropriate ones to classify students into masters and non- masters. The college instructors' large preoccupation and exerting their utmost efforts to teach may dispose of them from other evaluation strategies. The reason for the college instructors' use of the paper-and-pencil strategy can be explained as those college instructors were evaluated in the same strategy by their former teachers. Hence, they will not simply exclude this strategy. As for the worksheets, they are a kind of modern -evaluation strategies practiced by some college instructors.

Results related to the second question: What is the degree of knowledge and practice of Ajloun University College instructors of the realistic evaluation instrument?

This question was answered by responding to the second part of the questionnaire, which presented the college instructors' responses (males and females separately). Their responses were in the form of frequencies and percentages to answer (yes) to the item "Yes I know", or (yes) for " I use". See table (2).

Table (2), through the responses to items (3 and 12), shows that the college instructors' knowledge of the checklists and observation instruments got (100\%). Their use of achievement files previously prepared got (15.7\%). These results are consistent with Airasian (2005) view that college instructors usually use paper and electronic strategy for achievement files.

Expected results from the use of electronic achievement files to evaluate students for previous learning outcomes: Modern methods of evaluation may provide information that helps govern and decide many disciplines of the educational institution and the educational system, including: -

First: The quality of student learning: The quality of education does not mean the purposes of what an individual stored in his or her portfolio of scores as a result, but:

- The extent of his or her ability to understand the material and how to use it in his or her professional and daily life.

- The ability to solve questions.

- Helping the student to be more effective and able of being self-evaluated, self-directed, more integrated, and effective in the teaching and learning process.

- The extent of his or her contribution to the development of society.

Second: The quality of the educational process: The extent of the dynamism of the educational process in the classroom, and the extent to which it has achieved the goals of the program in terms of the scientific level. It expresses methods of performance used and levels of thinking to develop it.

Evaluating the students' results gives the teachers indicators about the need to activate the educational process and the aspects that should be developed. It starts with the specific objectives of the subject as educational products. Then, it deals with the learning methods to choose evaluation instruments that can judge the extent to which the students achieve the objectives.

Table 2. Frequencies and percentages of college instructors who answered (yes) for "I know the instrument", and (yes) " I use the instrument."

\begin{tabular}{|c|c|c|c|c|c|c|c|c|c|}
\hline \multirow{2}{*}{ Number } & \multirow{2}{*}{ The Instrument } & \multicolumn{4}{|c|}{$\begin{array}{l}\text { Frequencies and Percentages of College Instructors } \\
\text { who answered (yes) to "I know the instrument" }\end{array}$} & \multicolumn{4}{|c|}{$\begin{array}{c}\text { Frequencies and Percentages of College } \\
\text { Instructors who answered (yes) to "I use the } \\
\text { instrument" }\end{array}$} \\
\hline & & $\begin{array}{l}\text { Males' } \\
\text { Number }\end{array}$ & $\begin{array}{l}\text { Males' } \\
\text { Percentage }\end{array}$ & $\begin{array}{l}\text { Females' } \\
\text { Number }\end{array}$ & $\begin{array}{l}\text { Females' } \\
\text { Percentage }\end{array}$ & $\begin{array}{l}\text { Males' } \\
\text { Number }\end{array}$ & $\begin{array}{l}\text { Males' } \\
\text { Percent } \\
\text { age }\end{array}$ & $\begin{array}{l}\text { Females' } \\
\text { Number }\end{array}$ & $\begin{array}{l}\text { Females' } \\
\text { Percentage }\end{array}$ \\
\hline 1 & $\begin{array}{l}\text { Achievement } \\
\text { File } \\
\end{array}$ & 4 & $9.3 \%$ & 2 & $4.2 \%$ & 1 & $23.3 \%$ & 6 & $12.5 \%$ \\
\hline 2 & Projects & 15 & $34.9 \%$ & 20 & $41.7 \%$ & 0 & $00.0 \%$ & 0 & $00.0 \%$ \\
\hline 3 & Checklists & 43 & $100 \%$ & 48 & $100 \%$ & 29 & $67.4 \%$ & 44 & $91.7 \%$ \\
\hline 4 & Verbal Rubric & 32 & $74.4 \%$ & 37 & $77.1 \%$ & 17 & $39.5 \%$ & 32 & $66.7 \%$ \\
\hline 5 & Rubric & 36 & $83.7 \%$ & 41 & $85.4 \%$ & 18 & $41.9 \%$ & 27 & $56.3 \%$ \\
\hline 6 & $\begin{array}{l}\text { Learning-Descrip } \\
\text { tion Record }\end{array}$ & 10 & $23.3 \%$ & 8 & $16.7 \%$ & 0 & $00.0 \%$ & 2 & $4.2 \%$ \\
\hline 7 & Anecdote & 5 & $11.6 \%$ & 6 & $12.5 \%$ & 0 & $00.0 \%$ & 1 & $2.1 \%$ \\
\hline 8 & Student's Diary & 0 & $00.0 \%$ & 1 & $2.1 \%$ & 0 & $00.0 \%$ & 0 & $00.0 \%$ \\
\hline 9 & $\begin{array}{c}\text { Evaluating } \\
\text { Others }\end{array}$ & 28 & $65.1 \%$ & 36 & $75.5 \%$ & 7 & $16.3 \%$ & 6 & $12.5 \%$ \\
\hline 10 & Self-Evaluation & 29 & $67.4 \%$ & 42 & $87.5 \%$ & 10 & $23.3 \%$ & 9 & $18.8 \%$ \\
\hline 11 & The Interview & 38 & $88.4 \%$ & 39 & $81.3 \%$ & 3 & $7.0 \%$ & 7 & $14.6 \%$ \\
\hline 12 & Observation & 43 & $100 \%$ & 48 & $100 \%$ & 43 & $100 \%$ & 48 & $100 \%$ \\
\hline
\end{tabular}


Third: The quality of the used evaluation: The recent reforms, of the quality of education, focus on processes and learning outcomes. These are essential and important indicators of judging the quality of the learning process or outputs represented by the student and of the educational institution. The concept of evaluation, regarding quality and accreditation, goes beyond just conducting tests that include editorial questions. They measure simple knowledge and skills that take place in specific periods for a more comprehensive concept. It is a transition from simple editorial tests to multiple evaluation ones, from measuring simple knowledge and skills into measuring a higher level of thinking. It is a phase of measuring knowledge into how it is used in professional and public life regarding the emotional aspects of values and attitudes (Abdul- Hafeez, 2010:1165).

\section{Achievement- File (Portfolio) Assessment}

The achievement- file assessment has received increasing attention, and it has become an integral part of the classroom calendar in the developed countries, especially the United States of America. It is prominent in many European countries, such as the Netherlands and England. It has been also used in many large-scale calendar programs such as the national assessment and the final assessment at the end of the educational stages. A portfolio can include a sample of students' work that is more extensive than a performance task or a single product. It can also be a sample of students 'class activities in languages, mathematics, science, and society, and arts to document their growth. It can be used to know the extent to which they achieve educational goals and the expected desired levels.

\section{Portfolio Planning and Composition, and How to Evaluate It}

A portfolio requires planning, so it is not merely a wallet full of papers and not directed at educational goals or expected levels. (Nitko, 1996; Popham, 1995) explained the steps for preparing an evaluating sample for the portfolio:

1. Determining the purpose of the portfolio: There are different portfolios. The teacher should determine the purpose of the evaluation. The purpose is, sometimes, to know the best actions of the student, the strengths and weaknesses of the student enhance the strengths and overcome the weaknesses. Some portfolio parts can be used for over one purpose. Here, the teacher prefers to classify the contents of the portfolio into separate sections.

2. Defining the content and skills to be evaluated: The portfolio evaluation requires specifying what the teacher expects to find in the student's achievement file. The teacher should guide the student to carry out the educational goals that should be determined in terms of content, the skills, and the decision that he or she will reach.

3. Determining the target study class: This depends on the purpose of the portfolio evaluation. Hence, if the teacher aims to provide feedback to all students and their parents, this requires the collection of multiple assignments for these students. And if it aims to collect diagnostic information. Then, it may need to collect information from selected assignments limited to certain contents and skills. However, if the purpose is to take part in a higher evaluation, as the national evaluation, this imposes certain classes and the repetition of collecting different assignments of these students.

4. Determining the assignments that will be collected: It also depends on the purpose of the portfolio evaluation. Thus, if the purpose is to present the student's work, the Portfolio should include only the best of these assignments. And in this case, the content of the assignments may vary. These assignments include written and oral materials and products such as paintings, audiovisual recordings, pictures, and others. But if the purpose is to document the student's progress, the contents of the portfolio must reflect the gained skills. The portfolio includes samples of the student's completed and ongoing assignments, descriptive records, presentations, and lists of books he or she has seen. It also includes mathematical issues he or she has solved, laboratory experiment reports, projects he or she has undertaken, group activities, computer outputs, artistic productions, maps, drawings, shapes, and others.

5. Determining the number of times the assignments are collected. It depends on the portfolio, so if Portfolio is the best work that is required, then assignments can be collected after the student finishes his or her best work. Still, if Portfolio documentation of progress is required, it is to collect a sample of the assignments via extended time.

6. Setting a plan for students' participation in the formation of their assignment files: One advantage of using portfolios in the classroom evaluation is the possibility of students taking part in the evaluation of their work, as they can help in choosing the assignments that will be included in the portfolio, and they can also share their peers with them in the assignments and follow them, and it can also be organizing meetings with the teacher or with parents to exchange views on these assignments. It was also possible to identify assignments of the students who were self-evaluated to encourage them to show their written and oral reflections before the teacher and their peers. This required training for students on how to do this and practice it. 
7. Setting a plan for estimating the portfolio grades: This requires a decision regarding how to estimate the original work that the Portfolio includes and whether the assessment is comprehensive or limited to some assignments. This depends on the purpose of the evaluation and the educational goals to achieve and clarify.

\subsection{Portfolio's Grades Estimation}

Portfolio grading requires preparation of performance criteria, as in estimating grades of performances and outputs that we explained earlier. A portfolio included a set of actions of performances and outcomes. Therefore, the methods of building these criteria, and how to prepare scales for estimating the degrees we cover, also apply to Portfolio. However, attention should be paid to the grading system in this case, as students may get different grades in their files depending on how the total degree was derived. It is observed that the grades of the system, relying on finding the average of the student's grades of work included in a file, are based on different criteria. It is marred by many errors that reduce the consistency of these degrees. Students' achievement files required for all teachers in a particular class, or to be transferred to the next one, should be analysed by concerned teachers in performance criteria. This helps all teachers focus on the same class or the next one during the teaching process regarding these performances' inclusion of knowledge and skills (Stecher \& Herman, 1997).

The portfolio also helps get the consistency of grades or ratings across the different grades. And students can be allowed to take part in determining the performance criteria used in evaluating the content of their assignment files. They will be allowed to feel the authenticity of these files, think well about their contents, and what work they will include. The teacher can, at the beginning of the lesson, discuss students about the criterion which makes a research report or give them oral reading or distinct laboratory experience. Thus, the portfolio becomes a system that serves the teaching process and the processes of learning and evaluation. It can examine some students' achievement files to know their sufficiency, which must be added to, deleted from, or amending the performance criteria following the educational goals.

Estimating portfolio scores vary according to its purpose and content. If the purpose is to provide descriptive information about the student's performance, to be discussed with parents, it is not to estimate grades for the portfolio's content. The contents themselves provide the required information. However, if the purpose is to transfer the student to a higher class or evaluate the effectiveness process, estimating grades for portfolio parts becomes necessary. Checklists, numerical, graphical, descriptive assessment scales can be introduced.

\subsection{Reliability of Portfolio's Grades Estimation}

The teachers use portfolio evaluation to make decisions related to students, validity, and consistency should characterize its results. They should evaluate the contents of the Portfolio as performances and outputs. The requirements, that guarantee the validity, consistency, and fairness of their grades, should be achieved. Using a Portfolio is intended to increase the validity of the measurement. However, there is not enough evidence to support this. Many errors affect the reliability of these estimates when the teacher made a comprehensive evaluation of the Portfolio. Many of the exotic variables could affect this evaluation such as the student's handwriting and coordination of his or her work. Thus, care should be taken of these and other variables to ensure the validity and reliability of the estimations.

The selection of the portfolio contents and the procedures, for estimating its grades, require more attention from the teacher. The validity and consistency of the estimates depend on the extent to which the tasks, that the Portfolio includes, are the desired educational goals. The purpose of the evaluation is to overcome questions about biased assessments such as lenient errors and the aura that affected the relevant steps of building criteria for assessing performance and outcomes. This can be done by preparing scales for assessing grades and training students to prepare and use these scales.

Finally, evaluating performance, product and portfolio are not different from the traditional evaluation methods like using the written tests. It is possible to follow methodological methods to reduce many of these questions that affect the validity and consistency of the evaluation results.

\subsection{Computerized Evaluation}

The theoretical framework of contemporary educational evaluation abounds in multiple methods of what is called computerized evaluation or computer-based evaluation, multimedia, and the Internet. Many developed countries have considered the use of information technology (IT) in the educational evaluation as indispensable. This is because computers and related technologies have gained a great interest in designing, building, applying, correcting, and evaluating tests and other evaluation instruments. We will explain some applications below:

1. Electronic Portfolio: The Portfolio is prevalently used to express students' distinct products and multiple strategies for these products. It helps the portfolio include more information to educational goals or expected levels of information that can be displayed in various forms such as animation, simulation, television pictures, projects, and multimedia presentations. It is also possible to store portfolios supplements on the integrated tapes. 
2. Computer-based tests: Computers have brought about fundamental changes in the methods and methods of building, applying, correcting, and analysing their results. Computer-based tests are those tests that the computer applies, either by the computer alone or through a computer network, or any technology connected to the Internet. Some testing institutions in the United States of America have prepared guidelines to help ensure high-quality measurement by computer-based tests and the internet-based calendar. These guides have become complementary and expanded to the standards and levels published by the American Psychological Association.

3. Computerized Matching Tests: The written tests are an important component of the students' final evaluation. Major developments have occurred in information technologies and contemporary psychometric theories. The modern theory of measurement of Item-Response Theory allows students to be evaluated more effectively and accurately. It is because the vocabulary is selected from a bank of questions that have been calibrated, so it complies with the students' ability levels.

4. Computerized Question Banks: The teacher needs to change the tests he or she applies to students each year, building new tests that often lack scum characteristics. Therefore, the use of computerized question banks helps in overcoming many of the questions of designing and building tests periodically. Establishing question banks depends on the item-response theory, especially the Rash Model where all the vocabularies of multiple tests are adjusted on a common scale for each subject. The scale shows the relative difficulty of the vocabulary, which can be developed without the need for extensive experimentation.

The future vision of the college members' use of the (paper- electronic) achievement files while evaluating their students faces many challenges. The most important challenges facing universities in this era are the rapid developments in all fields. Whenever the university achieves success in its outputs, new aspirations are imposed by an accelerated life. Hence, the importance of evaluating students with modern methods, to raise the quality of university performance, should be taken into consideration.

\subsection{Expected Measured Learning Outcomes by Using These Methods}

These modern methods (the paper- electronic achievement file) are used to evaluate the learning expected from students in several fields and describe the learning outcomes at each level. These domains are:

Knowledge: The ability to retrieve, understand and present information which included
- Knowing certain facts.

- Knowledge of specific concepts, foundations, and theories.

- Knowledge of specific procedures.

Ensuring students' perception: the concept of the achievement file, its types, advantages, and organization, how to use it in their assessment, and other aspects of the file culture, should be taught to the students.

- Planning student evaluation requirements based on the specifications required by graduates.

- Developing student evaluation systems based on academic standards.

- Developing examination systems to achieve targeted educational outcomes.

- Preparing and updating question banks for courses considering targeted learning outcomes and academic standards for programs that serve specialization.

- Explaining the work included in the file, and how it should be accomplished: compulsory, optional, individual, cooperative, and theoretical assignments.

- Formerly agreement with students on evaluating procedures and rules for assessing their performance.

- Continuous monitoring of the efforts of each student in his or her file, with guidance and feedback.

- Constantly encouraging students to assess their assignments and their peers' ones within the file to support learning.

- The availability of electronic achievement files as instruments for the real evaluation allows students to express the implications of their learning for their actual practices (showing the actual relationship between theory and practice).

\subsection{Cognitive Skills Included the Ability to:}

- Apply conceptual perception of terms, principles, and theories.

- Apply the methods involved in critical thinking and creative solution to questions, whether at the request of others or when facing new and unexpected situations.

- Study topics and questions in a field of study using a variety of diverse sources and extract valid conclusions.

\subsection{Interpersonal Skills and Responsibility Included} the Ability to

- Take responsibility for their learning and continue to develop personal and professional.

- Work in a group effectively and practice driving when needed.

- Act responsibly in personal and professional relationships.

Act ethically and adhere to high moral values on a personal and social level. 
10.7. Communication Skills, Information Technology, and Numerical Skills Which Included the Ability to:

- Do verbal and written communication effectively.

- Use communication and information technology.

- Use basic mathematical and statistical methods.

\subsection{Psycho -Motor Skills}

\subsubsection{Physical Ingenuity}

These skills are of great importance in some fields of study. For example, psycho -motor skills are required at a top level for surgeons, artists, and musicians.

\section{Conclusions}

To achieve the future vision of using (paper- electronic) achievement files as a means for a comprehensive evaluation of all aspects of students' college learning, the researcher suggests the following: There is a need to educate teachers about developing student's evaluation systems. The study suggests improving the educational system to ensure its quality, by spreading the culture of evaluation and educating students about their roles and what is required of them. Besides, this study suggests providing students with instruments, guiding them to the resources that would help them accomplish their work included in the file. This study encourages the continuous training of college instructors on realistic evaluation methods (achievement files). This can be done by increasing the awareness of college instructors and decision-makers of the realistic evaluation (achievement files), its methods, and importance. There should be financial allocations for implementing realistic evaluation methods (achievement files) at the university. Future research can avail from this study by conducting a comparative study between the modern realistic (achievement files) evaluation strategies as opposed to the traditional ones.

\section{REFERENCES}

[1] Abed Al-Hafeez, Sa'eed (2010). Modern Trends in Evaluating Students from the Perspective of Quality and Academic Accreditation. The Arab Journal for Security Studies and Training, 25(50), 165-166.

[2] Afaneh, Muhammad (2011). The Reality of Arabic Language Teachers' Use of Assessment Methods in UNRWA Middle School in the Gaza Strip in Light of Recent Trends. (Unpublished Master's Thesis). Gaza: Islamic University.

[3] Airasian, P. (2005). Classroom Assessment: Concepts and Applications. 5th Ed. Boston: McGraw- Hill.
[4] A'llam, Salahuddin (2015). The Measurement and Educational Evaluation in the Teaching Process. Amman: Al-Maseera Publishing House.

[5] Al-Rifa'i, Abeer, Al-Tawalbeh, Hadi, Al-Qaoud, Ibrahim (2012). The Degree of Practice of Social Studies Teachers in Ajloun Governorate for Realistic Evaluation Strategies. Umm Al-Qura University Journal of Educational and Psychological Sciences, 4 (1), 369-408.

[6] Arter, J, Spandel, V. (1992). "Using the Portfolios of Student Work in Instruction and Assessment." Instructional Topics in Educational Measurement, 30-44.

[7] Barrett, H. (2007). Reaching Electronic Portfolios and Student Engagement: The Reflect Initiative. Journal of Adolescent and Adult Literacy, 50(6), 436.

[8] Beresfor, Wendy, Cobham, David (2010). The Role of E-Portfolios in Higher Education: Their Perceived Value Potential to Assist Undergraduate Computing Students, http://epritns.lincoln.ac.uk/3871/2/eportfolio.pdf.

[9] Gay, L \& Airasan, P. (2003). Educational Research. 4th Ed. New Jersey: Pearson Education, Inc.

[10] Gillespie C., Ford, Gillespie R., Leavell, A. (1996). "Portfolio Assessment: Some Questions, Some Answers; Some Recommendations." Journal of Adolescent and Adult Literacy, 39, 480-491.

[11] Keyser, S, Howell, L. (2008). The State of Authentic Assessment. Available Online:http://www.eric.ed.gov/./co ntent delivery/servlet/ ERICServlet? Accno (ED503679).

[12] Lambert Connie, Depaepe, Jim, Lambert, Larry, Anderson, Denise (2007). E-Portfolios in Action. Kappa Delta Pi Record, 43 (2), 76-81, Retrieved October 24, 2009.

[13] Lopez- Fernandez, Oltaz, Rodriguez-Illera, Jose Luis (2009). Investigating University Students' Adaptation to a Digital Student Course Portfolio. Computers and Education, 52, 608-616. https://doi.org/10.1016/j.compedu.2008.11.003.

[14] McMillan, J. (2001). Essential Assessment Concepts for Teachers and Administrators. CA: Corwin Press, Inc.

[15] Mueller. Jon (2012). The Authentic Assessment Toolbox: Enhancing Student's Learning through Online College Development. Retrieved 8/9/2012 from http://jfmueller college. noctrl.edu.

[16] Nitko, A. (1996). Educational Assessment of Students. Englewood Cliffs, N. J.: Merrill.

[17] Ozgur, Aydin, Kaya, Secil (2011). The Management Aspect of the E-Portfolio as an Assessment Instrument: Sample of Anadolu University. TOJET: The Turkish Online Journal of Educational Technology, 10(3), 296-303.

[18] Popham, J. (1995). Classroom Assessment: What Teachers Need to Know. Boston: Allyn and Bacon.

[19] Stecher, B., Herman, J. (1997). "Using Portfolios for Large Scale Assessment" in Gary D. Phye (Ed.). Handbook of Classroom Assessment (pp. 491-516). London: Academic Press Limited.

[20] Suskie, L. (2004). Assessing Student Learning: A Common Sense Guide. Anker Publishing Company. 
[21] Suurtamm, C. (2012). Assessment Can Support Reasoning and Sense. The Mathematics Teacher Journal, 106(1), 28-33. DOI: 10.5951/mathteacher.106.1.0028.

[22] Wang, S. (2004). Learning Experiences in Developing Electronic Portfolios in a Master Educational Technology Program: A Case Study (Dissertation). Ohio University, Instructional Technology (Education), 211.
[23] Wang, S. (2007). Roles of Students in Electronic Portfolio Development. International Journal of Technology in Teaching and Learning, 3(2), 17-28.

[24] Zellers, M., Mudrey, R. (2007). Electronic Portfolios and Meta-Cognition: A Phenomenological Examination of the Implementation of E-Portfolios from the Instructors' Perspective. International Journal of Instructional Media, 34(4), 419-430. 